* Doutor em Administração da Saúde, vinculado ao Centro de Administração e Políticas Públicas (CAPP), Lisboa, Portugal. E-mail: anunes@iscsp. ulisboa.pt

** Licenciada em Direito, jurista no Ministério da Saúde, vinculada à Faculdade de Direito da Universidade de Lisboa. E-mail: rosa.raposeiro@ms.gov. $\mathrm{pt}$

\section{Direito À Saúde Em Portugal: Enquadramento Constitucional E O Desenvolvimento Do Serviço NaCional De Saúde}

\author{
Right to Health in Portugal: A Constitutional \\ FrameWORK AND THE DEVELOPMENT OF THE NATIONAL \\ HealthCARE System
}

\author{
Alexandre Morais Nunes* \\ Rosa Raposeiro**
}

Como citar: NUNES, Alexandre Morais; RAPOSEIRO, Rosa. Direito à saúde em Portugal: enquadramento constitucional e o desenvolvimento do serviço nacional de saúde. Revista do Direito Público, Londrina, v. 14, n. 3, p. 35-48, dez. 2019. DOI: 10.5433/24157-108104-1.2019v14n3p. 35. ISSN: 1980-511X

Resumo: Em Portugal, o direito à proteção da saúde encontra-se consagrado no artigo $64^{\circ}$ da Constituição da República Portuguesa, que na sua redação original, realiza-se através da implementação de um serviço nacional de saúde, e de um conjunto de condições (sociais, sanitárias, econômicas e culturais) que garantem a proteção de todos os cidadãos e contribuem para a melhoria geral das condições de vida e de trabalho. Ao nível da assistência em saúde, a criação do Serviço Nacional de Saúde (SNS), em 1979, foi um dos grandes passos dados no cumprimento deste desígnio constitucional, garantindo um acesso universal (para todos), geral (todas as especialidades) e gratuito. O presente artigo tem por objetivo descrever, através da revisão da legislação publicada e da literatura especializada, o trajeto do direito à saúde desde 1976 até aos dias de hoje, considerando as várias revisões constitucionais e o desenvolvimento do SNS.

Palavras-chave: Direito à saúde. Acesso. Constituição da República Portuguesa. Serviço Nacional de Saúde.

Abstract: In Portugal, the right to healthcare is enshrined in Article 64 of the Constitution of the Portuguese Republic, which, in its original form, is implemented through the enforcement of a national healthcare service and conditions (social, health, economic and cultural) that covers every citizen and contributes to the general improvement of living and working conditions. At the current level of healthcare delivery, the creation of the National Healthcare System (NHS) in 1979 was a major step 
in guaranteeing healthcare universally (for all), generally (all specialties) and free of cost. The purpose of this paper is to describe, through the exploration of published legislation and literature on this topic, the path of the right to healthcare from 1976 to present day, whilst considering various constitutional revisions and the creation of the NHS.

Keywords: Right to healthcare. Access. Constitution of the Portuguese Republic. National Healthcare System Service. 


\section{INTRODUÇÃO}

A saúde é uma das principais preocupações da população, sendo uma prioridade para os cidadãos, particularmente nos países com um modelo de Estado Social, nos quais o sector público é responsável por garantir a toda a assistência necessária (SILVA; PESTANA, 2013).

Em Portugal, o direito universal à saúde foi definido pela primeira vez com a publicação da Constituição da República em 1976 (REPÚBLICA PORTUGUESA, 1976), em vigor até aos dias hoje, sendo a sua oitava e última revisão datada do ano 2005 (REPÚBLICA PORTUGUESA, 2005).

O direito à proteção da saúde e o dever de a promover encontra-se consagrado no artigo 64. ${ }^{\circ}$ da Constituição da República Portuguesa, que na sua redação original, se realizaria através da criação de um serviço nacional de saúde, e pela criação de um conjunto de condições de adequadas económicas, sociais e culturais que garantissem a proteção da infância, juventude e da velhice, da promoção da cultura física e desportiva, escolar e popular, da promoção da educação sanitária e ainda da melhoria geral das condições de vida e de trabalho dos cidadãos (REPÚBLICA PORTUGUESA, 1976).

As disposições constitucionais foram implementadas três anos após a publicação da Constituição da República Portuguesa de 1976, com a criação do Serviço Nacional de Saúde (SNS) pela Lei n. ${ }^{\circ}$ 56/79, de 15 de setembro (REPÚBLICA PORTUGUESA, 1979).

O Serviço Nacional de Saúde atualmente de gestão descentralizada e participativa. Surgiu como uma forma do Estado concretizar o seu papel de proteção da saúde dos seus cidadãos (CAMPOS, 2008), de acordo com as normas constitucionais da universalidade (para todos os cidadãos), generalidade (em todas as necessidades de saúde) e de forma gratuita para todos os cidadãos. Essa redação inicial do artigo $64^{\circ}$ da Constituição da República Portuguesa referente ao direito à proteção da saúde foi objeto de três emendas constitucionais: em 1982 (onde foi incluída a gestão descentralizada e participada para o SNS), em 1989 (onde é afastado o principio da gratuidade com a previsão da sua tendencial gratuidade e redefinida a sua finalidade) e em 1997 (foi ajustada a redação constitucional ao desenvolvimento do Serviço Nacional de Saúde).

Como imposição constitucional, a existência de um serviço público de saúde para todos os cidadãos ganhou uma forma que ultrapassa a vontade política (NOVAIS, 2010, a), cabendo ao Governo manter os princípios constitucionais na sua ação estratégica para a política de saúde e na definição de áreas prioritárias de intervenção, sempre promovendo o acesso, a eficiência e não negligenciando a qualidade (NUNES, 2016). No entanto, em termos jurídicos, se ocorrer uma extrapolação dos poderes e se verificar uma intenção ou mesmo limitação da prestação da assistência em saúde, o Governo incorre em um não cumprimento/violação da Lei que será sujeita numa instância superior à análise e julgamento por parte do Tribunal Constitucional (NOVAIS, 2011).

Desde a criação do SNS, a prestação de cuidados de saúde em território nacional passou a ser assegurada por um conjunto de unidades públicas e convencionadas, distribuídas por todo 
o território nacional ao nível da assistência básica, diferenciada, pós hospitalar (continuada) e paliativa (FERNANDES, 2015).

O presente artigo tem por objetivo descrever, através da revisão da legislação publicada e da literatura nacional da especialidade, o trajeto do direito à saúde desde o ano de 1976 até aos dias de hoje (2018), considerando as várias revisões constitucionais, as delimitações jurídicas fundadas na jurisprudência emitida pelo Tribunal Constitucional e o desenvolvimento do Serviço Nacional de Saúde.

\section{O DIREITO À SAÚDE: DELIMITAÇÃO CONSTITUCIONAL}

A Constituição da República Portuguesa enquadra-se em um modelo de Estado Social e de direito democrático que além dos direitos clássicos de liberdade, contém uma ampla gama de direitos sociais que exigem respeito por parte dos titulares políticos da área da saúde (NOVAIS, 2010 , a, p. 20). Isso significa que os direitos atribuídos pela constituição aos cidadãos não podem ser alvo da vontade política e, por isso, não podem ser encarados como uma qualquer benesse que se possa retirar ou atribuir aos cidadãos em qualquer momento, exceto com a revisão da Lei constitucional.

O direito de proteção à saúde, é um direito social previsto no artigo $64 .^{\circ}$ da Constituição. Na sua redação original (REPÚBLICA PORTUGUESA, 1976), estava reconhecido que todos os cidadãos têm direito à proteção da saúde e o dever de a defender e promover (n. $\left.{ }^{\circ} 1\right)$, proteção essa realizada pela criação de um serviço nacional de saúde universal, geral e gratuito (n. ${ }^{\circ}$ ). Contudo, o artigo $64^{\circ}$ destacava ainda um conjunto de condições necessárias em complemento ao Serviço Nacional de Saúde e essenciais para promover a saúde e prevenir a doença, a referir: a " criação de condições económicas, sociais e culturais que garantam a protecção da infância, da juventude e da velhice e pela melhoria sistemática das condições de vida e de trabalho"; a "promoção da cultura física e desportiva, escolar e popular" e o "desenvolvimento da educação sanitária do povo".

Porém, a Constituição da República Portuguesa desde 1976 foi objeto de sete revisões Constitucionais encontrando-se atualmente na sua oitava versão:

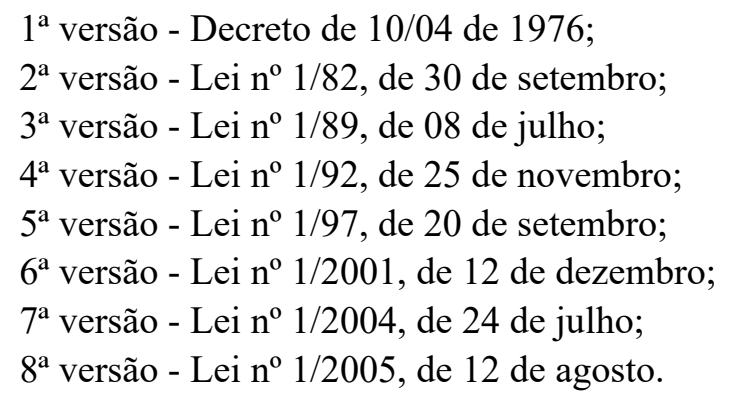

Apesar das sete revisões, o artigo $64 .^{\circ}$ sofreu alterações em três delas:

Primeira alteração ao artigo $64 .^{\circ}$ (através do artigo $54 .^{\circ}$ da Lei Constitucional 
n. ${ }^{\circ} 1 / 82$, de 30 de setembro), na qual foi aditado um n. ${ }^{\circ} 4$ ao artigo $64 .{ }^{\circ}$, com a seguinte redação: "4. O serviço nacional de saúde tem gestão descentralizada e participada". Com base nesta alteração foi possível descentralizar a gestão e criar as Administrações Regionais de Saúde dotadas de personalidade jurídica e com autonomia administrativa e patrimônio próprio e localizadas em cinco regiões (Norte, Centro, Lisboa e Vale do Tejo, Alentejo e Algarve), que quando criadas tinham como atribuições planejar e gerir coordenadamente as ações que envolvem a promoção da saúde, prevenção e tratamento das doenças e reabilitação, promovendo o máximo aproveitamento, ao menor custo, dos recursos existentes nas estruturas do sector público e privado da saúde (REPÚBLICA PORTUGUESA, 1982). Ao nível da gestão participada salienta-se a indicação em determinadas unidades de saúde nas denominadas unidades locais de saúde, que congregam a assistência na atenção primária e hospitalar, de um dos elementos do conselho de administração designado por parte da comunidade intermunicipal; Segunda alteração ao artigo $64 .^{\circ}$ (artigo $36^{\circ}$ da Lei Constitucional n. ${ }^{\circ} 1 / 89$, de 8 de julho) através da qual foram concretizadas alterações mais substanciais, tendo sido introduzido pela primeira vez o termo da "tendencial gratuidade" que conduziu nos anos 90 à previsão de taxas moderadoras no acesso à assistência à saúde providenciados pelo Serviço Nacional de Saúde, através do Decreto-Lei n. ${ }^{\circ}$ 54/92, de 11 de abril com a intenção não de limitar o acesso, mas sim de evitar o uso excessivo sem causa aparente;

Terceira alteração ao artigo $64^{\circ}$ (pelo artigo $37 .^{\circ}$ da Lei Constitucional n. $.^{\circ} 1 / 97$, de 20 de setembro) na qual são realizadas várias pequenas alterações de forma a ajustar a redação constitucional à linguagem, ao desenvolvimento do Serviço Nacional de Saúde e em conformidade com as políticas de saúde internacionais que vigoravam à data (como é exemplo a Carta de Ljubljana) que se mantém até hoje (CAMPOS; SIMÕES, 2011).

De acordo com o artigo 64. ${ }^{\circ}$ da Constituição da República Portuguesa, o Estado tem de garantir o direito à saúde a todos os cidadãos e em caso de incumprimento incorre num processo de inconstitucionalidade por omissão, que também está previsto na Constituição da República Portuguesa no seu artigo 283..

A fiscalização da constitucionalidade de acordo com o artigo $221 .^{\circ}$ da Constituição da República Portuguesa compete ao Tribunal Constitucional e pode realizar-se das seguintes de forma:

i) Abstrata-preventiva - realizada previamente à entrada em vigor de uma determinada norma (por pedido do Presidente da República, Primeiro-Ministro, Ministros da República ou por um quinto dos deputados da Assembleia da República);

ii) Abstrata-sucessiva - ocorre após entrada em vigor de uma norma;

iii) Concreta - Quando colocada em simultâneo com um processo a decorrer também em tribunal.

Na prática, a legislação protege os cidadãos garantindo-lhes o direito à saúde. Essa questão assume uma particular importância dado que até 1974, Portugal vivia um regime ditatorial, que não garantia a proteção da saúde aos cidadãos. Desde 1976, além de ser dada essa garantia, existe 
ainda fiscalização por parte do sistema de justiça que supervisiona e monitoriza o cumprimento desse direito e a satisfação de todas as necessidades na assistência à saúde.

\section{DA CONSTITUIÇÃO À CRIAÇÃO DE UM SERVIÇO NACIONAL DE SAÚDE}

No cumprimento do n. ${ }^{\circ} 2$ do artigo $64^{\circ}$ da Constituição da República Portuguesa foi criado, durante o V Governo Constitucional e no âmbito do então Ministério dos Assuntos Sociais, o Serviço Nacional de Saúde (SNS), através do qual o Estado assegura o direito à proteção da saúde, nos termos da Constituição.

Com a publicação da Lei n. ${ }^{o}$ 56/79, de 15 de setembro que cria o SNS, foi dado um grande passo e geradas as condições base para garantir o acesso universal, geral e com tendencial gratuidade envolvendo todos os cuidados integrados de saúde (incluindo atividades de promoção e vigilância da saúde, prevenção da doença, diagnóstico, tratamento e reabilitação médica e social).

Essas garantias de proteção da saúde referidas aplicam-se a todos os cidadãos nacionais (independentemente da sua condição económica e social), estrangeiros (em regime de reciprocidade), apátridas e aos refugiados políticos que residam ou se encontrem em Portugal. Esta garantia do SNS dada aos destinatários ficou condicionada no artigo 6. ${ }^{\circ}$ da Lei $n^{\circ}$ 56/79 pelas restrições impostas pelo limite de recursos humanos, técnicos e financeiros disponíveis. Por isso, cabe ao Serviço Nacional de Saúde assegurar a distribuição racional, a hierarquização técnica e o funcionamento coordenado dos serviços e definir a complementaridade de valências e promover a descentralização decisória e a participação dos utentes no planeamento e na gestão dos serviços.

O Serviço Nacional de Saúde tem no espectro jurídico uma autonomia administrativa e financeira, integrando órgãos centrais, regionais e locais.

Em termos de organização, o Serviço Nacional de Saúde português, é constituído por uma rede de órgãos e serviços sob direção unificada, gestão descentralizada e democrática e visa a prestação de cuidados globais de saúde a toda a população na atenção primária à saúde, diferenciada (hospitalar) (artigo $18 .^{\circ}$ ) e mais recentemente ao nível da assistência continuada pós hospitalares e também na assistência paliativos.

Desde a criação do Serviço Nacional de Saúde em 1979, várias mudanças legislativas tiveram efeitos no setor da saúde, sendo as principais destacadas na tabela a seguir:

Quadro 1 - Alterações legislativas com efeitos na Lei que instituiu o Serviço Nacional de Saúde português

Decreto-Lei n. ${ }^{\circ} 254 / 82$, de 29 de junho que revogou 46 artigos da Lei n $56 / 79$ de 15
de setembro.
Essa alteração foi declarada inconstitucional pelo Acórdão n. $.^{\circ} 39 / 84$, de 11 de abril
do Tribunal Constitucional que considerou que o diploma se traduzia "na extinção
do Serviço Nacional de Saúde" e como tal comprometeria a garantia do acesso à
assistência à saúde conforme à redação Constitucional em vigor desde 1976.


Lei $\mathrm{n}^{\circ}$ 48/90, de 6 de fevereiro (Lei de Bases da Saúde), alterada pela Lei $\mathrm{n}^{\circ}$ 27/2002, de 8 de novembro, que em linha com a segunda revisão constitucional prevê que "o Estado atue através de serviços próprios, celebra acordos com entidades privadas para a prestação de cuidados e apoia e fiscaliza a restante atividade privada na área da saúde" (.$^{\circ} 2$ Base IV) e determinou ainda ao invés da articulação formas empresariais e privadas da medicina com o SNS (conforme n. ${ }^{3} 3$ da Constituição da República Portuguesa em vigor à dará), que "É apoiado o desenvolvimento do sector privado da saúde e, em particular, as iniciativas das instituições particulares de solidariedade social, em concorrência com o sector público" (alínea f) do n. ${ }^{\circ} 1$ da Base II) e ainda a possibilidade de serem realizadas convenções ao nível da prestação de cuidados de saúde "podem ser celebradas convenções com médicos e outros profissionais de saúde ou casas de saúde, clínicas ou hospitais privados, quer a nível de cuidados de saúde primários quer a nível de cuidados diferenciados" (n. 1 Base XLI)

Estatuto do SNS, aprovado pelo Decreto lei $\mathrm{n}^{\circ} 11 / 93$, de 15 de janeiro - Revogou o Decreto-Lei n. ${ }^{\circ} 254 / 82$, de 29 de junho e derivou da incessante preocupação de propiciar aos utentes cuidados compreensivos e de elevada qualidade a fim de a compatibilizar com os princípios consagrados no capítulo II da Lei de Bases da Saúde. Numa perspectiva de organização e descentralização o Estatuto promoveu que a "gestão dos recursos se faça tão próximo quanto possível dos seus destinatários" criando as Administrações Regionais de Saúde.

Fonte: Elaboração própria.

Toda essa evolução permitiu um desenvolvimento contínuo da assistência em saúde realizada pelo Estado, que ano a ano ficou mais completa e com maior capacidade de resposta assistencial por todo o país. Em 2018, o SNS conta com um conjunto diverso de entidades de saúde, desde institutos públicos, unidades integradas no setor público administrativo e unidades integradas no setor empresarial do Estado:

a) Institutos Públicos

- Administrações Regionais de Saúde (Norte, Centro, Lisboa e Vale do Tejo, Alentejo e Algarve)

b) Unidades integradas no setor público administrativo (5 entidades)

- Centro Hospitalar Psiquiátrico de Lisboa

- Hospital Arcebispo João Crisóstomo

- Hospital Dr. Francisco Zagalo

- Centro de Medicina de Reabilitação Rovisco Pais

- Instituto de Oftalmologia Dr. Gama Pinto

c) Unidades integradas no setor empresarial do Estado (40 entidades)

- Hospitais

- Centros Hospitalares

$\mathrm{Na}$ prática, era esperado que todas essas unidades de saúde articulassem entre si na assistência à saúde. Porém, nem sempre ocorre essa interação e ainda existem algumas fragilidades 
no sistema, resultante entre outros aspetos, da dimensão, localização e grau de diferenciação na assistência à saúde.

\section{O ACESSO UNIVERSAL E GERAL NA ASSISTÊNCIA PÚBLICA À SAÚDE}

O acesso universal é consagrado tanto na redação original da Constituição da República Portuguesa "Todos têm direito à proteção da saúde" como em todas as suas versões, bem como na Lei que cria o Serviço Nacional de Saúde. De fato, o acesso ao SNS é garantido a todos os cidadãos de forma universal quanto à população abrangida" (LEI n. ${ }^{\circ}$ 48/90, base XXIV) e traduzse na assistência à saúde dirigida a todos os cidadãos nacionais e ainda estrangeiros (em regime de reciprocidade), apátridas e aos refugiados políticos que residam ou se encontrem em todo o território nacional.

Segundo a doutrina consolidada, o Tribunal Constitucional considera que o termo universal confere a todos o direito de recorrer à assistência no Serviço Nacional de Saúde e não impede o recurso aos serviços privados de saúde (CANOTILHO; MOREIRA, 2007; MIRANDA; MEDEIROS, 2005), nem o benefício incorrido por uma outra cobertura seja ela por um subsistema de saúde (seja ele de natureza pública ou privada) ou por um seguro privado voluntário (NOVAIS, 2010, b, 2011). Portanto, a inscrição de um cidadão num ubsistema de saúde ou adesão a um plano de saúde privado não lhe retira qualquer direito à saúde no âmbito do Serviço Nacional de Saúde, não existindo em caso algum a aplicação de uma imposição estatal para afastar um cidadão de um direito de assistência no SNS. Pelo exposto, a percentagem de cobertura do Serviço Nacional de Saúde é de $100 \%$, independentemente do seu uso ou opção individual de cada cidadão em outras alternativas.

Além disso, nos casos em que o acesso esteja de alguma forma comprometido por falta de capacidade de resposta e não for possível garantir a assistência em tempo adequado, o acesso poderá ser realizado por entidades convencionadas ((REPÚBLICA PORTUGUESA, 1979). Esta possibilidade segundo Miranda e Medeiros (2005), reforça a garantia do cumprimento da universalidade por parte do SNS.

O fato da política de saúde definida a cada ano poder verter uma ou outra área prioritária muitas das vezes direcionada a grupos de cidadãos mais expostos e com maiores riscos não pode ser entendida como um comprometimento do acesso universal, pois a titularidade da prestação é que é universal, mas o dever de promover a saúde poderá ser diferenciado (NOVAIS, 2011).

Um outro ponto que até mais recentemente reforça a universalidade no acesso no Serviço Nacional de Saúde foi a implementação do Livre Acesso e Circulação (Despacho n. ${ }^{\circ}$ 5911-B/2016, de 3 de maio), que permite ao utente que necessita de uma primeira consulta de especialidade, juntamente com o seu médico de família (responsável pelo encaminhamento) possa tomar a liberdade de escolher a instituição que lhe vai prestar cuidados de saúde de acordo com um conjunto de critérios que têm em conta o interesse do próprio utente e família, a proximidade geográfica e os tempos de resposta/lista de espera da instituição de destino (SIMÕES; AUGUSTO; 
FRONTEIRA, 2017).

Quanto ao princípio da generalidade, esse é enunciado na própria Lei que cria o Serviço Nacional de Saúde "O SNS envolve todos os cuidados integrados de saúde, compreendendo a promoção e vigilância da saúde, a prevenção da doença, o diagnóstico e tratamento dos doentes e a reabilitação médica e social" (REPÚBLICA PORTUGUESA, 1979) e também na Lei de Bases da Saúde "Prestar integradamente cuidados globais ou garantir a sua prestação" (REPÚBLICA PORTUGUESA, 1990).

O termo geral abrange todos os serviços públicos de saúde e todos os domínios e prestações, o que significa a garantia de prestação de total assistência à saúde. De fato, a generalidade na prestação envolve uma ampla gama de serviços de saúde com resposta para todas as necessidades dos cidadãos desde: a atividade preventiva e de promoção e vigilância de saúde realizada sobretudo ao nível da atenção primária à saúde; a vertente curativa num nível mais diferenciado/especializado de assistência tradicionalmente conhecida como cuidados de saúde hospitalares; a realização de meios complementares de diagnóstico em unidades públicas ou privadas com convenções (acordos de complementaridade com o sector público) e ainda assistência na reabilitação médica de curta, média ou longa duração e/ou sociais integrados numa rede de assistência continuada e ainda a prestação de assistência paliativa. No entanto, de acordo com a redação da Lei que cria o SNS (REPÚBLICA PORTUGUESA, 1979), a garantia de assistência compreende o acesso a toda a demanda do Serviço Nacional de Saúde e não sofre restrições exceto as impostas pelo limite de recursos humanos, técnicos e financeiros disponíveis.

Embora presentes os princípios de universalidade e generalidade na Constituição da República Portuguesa e por consequência no Serviço Nacional de Saúde, a verdade é que ainda existe assistência que não é abrangida pelo Serviço Nacional de Saúde ou que têm ainda uma fraca resposta. Como exemplo, é possível referir os elevados tempos de espera em algumas especialidades médicas, da assistência em saúde bucal, da resposta às necessidades na assistência continuada e paliativa e ainda ao nível do paciente com problemas de saúde mental.

\section{A TENDENCIAL GRATUITIDADE E A IMPLEMENTAÇÃO DE TAXAS MODERADORAS NO SERVIÇO NACIONAL DE SAÚDE}

Como referido nos capítulos anteriores, o acesso ao SNS no momento da sua criação, em conformidade com a Constituição da República Portuguesa vigente à data, era gratuito para todos os cidadãos independentemente da sua condição económica ou social. Contudo, a Lei que cria o Serviço Nacional de Saúde deixou uma abertura ao fim da total gratuidade quando no seu artigo 7. ${ }^{\circ}$ referindo que esse acesso é gratuito, mas sujeito ao estabelecimento de taxas moderadoras com objetivo de racionalizar a utilização.

Após a publicação do diploma foi emitido um parecer pela então Comissão Constitucional, que reconheceu que o caráter eminentemente programático como medida para fazer comparticipar os utentes no custo das prestações ou cuidados de saúde, de modo a evitar ou minorar os abusos 
(v.g. de consumos) excessivos e desnecessários.

A introdução do termo "tendencialmente gratuito" na Revisão Constitucional de 1989 foi logo efetivado no ano seguinte com a publicação da Lei de Bases da Saúde que referia que as taxas moderadoras tinham por objetivo "completar as medidas reguladoras do uso dos serviços de saúde, podem ser cobradas taxas moderadoras, que constituem também receita do Serviço Nacional de Saúde" e introduziu igualmente um conjunto de isenções ao pagamento atribuídas aos grupos populacionais sujeitos a maiores riscos e os financeiramente mais desfavorecidos, nos termos determinados na lei.

A Lei de Bases da Saúde ainda determinou que deveria ser especificado por lei a assistência garantida aos beneficiários do Serviço Nacional de Saúde e excluiu do objeto a assistência não justificados pelo estado de saúde.

A questão da constitucionalidade da aplicação das taxas moderadoras foi colocada em causa ao longo dos anos. A grande crítica assentava pelo fato de saber se os limites constitucionais da universalidade eram compatíveis com o pagamento a cargo dos cidadãos (NOVAIS, 2006).

Em termos de arbitragem, uma vez que o direito à saúde está legalmente estabelecido na Constituição da República Portuguesa, cabe ao Tribunal Constitucional garantir a constitucionalidade das políticas de saúde. Assim, no âmbito da fiscalização abstrata o Tribunal Constitucional foi algumas vezes suscitado a pronunciar-se sendo de referir:

a) Em 1984, o Acórdão 39/84 relativamente à constitucionalidade do Decreto-Lei n. ${ }^{\circ}$ 254/82, de 29 de junho que revogava 46 artigos da Lei ${ }^{\circ} 56 / 79$ de 15 de setembro (artigos $18 .^{\circ}$ a $61 .^{\circ}$; $\operatorname{artigo} 64 .^{\circ}$ e artigo $65 .^{\circ}$ da Lei n. ${ }^{\circ}$ 56/79, de 15 de setembro). O Tribunal de Contas considerou que este diploma representava um retrocesso e continha o risco de comprometer o acesso através da extinção do Serviço Nacional de Saúde. Assim foi declarada a sua inconstitucionalidade por violação do artigo $65 .^{\circ}$ da Constituição da República Portuguesa;

b) Em 1989, o Tribunal Constitucional voltou a pronunciar-se através do Acórdão n. ${ }^{\text {o }}$ 330/89, referindo que a introdução do pagamento de taxas moderadoras pelos utentes do Serviço Nacional de Saúde não constituía uma inconstitucionalidade. O Tribunal Constitucional entendeu o conceito normativo da gratuidade como "um certo halo de indeterminação" pois o utente não teria de pagar qualquer contrapartida, mas sim para salvaguardar o individual e total com efeitos de suporte da prestação e ainda pelo facto da aplicação de taxas estar associada à racionalização da procura procurando dissuadir o acesso abusivo e sem justificação aos serviços públicos de saúde.

c) Em 1995, através do Acórdão n. ${ }^{\circ}$ 731/95, o Tribunal Constitucional pronunciou-se sobre o tema da incompatibilidade entre a aplicação de taxas moderadoras e o acesso universal aos cuidados de saúde do SNS, concluindo que a tendencial gratuidade tratava-se de uma forma de flexibilização da redação original não constituía uma inconstitucionalidade. $\mathrm{Na}$ fundamentação era considerado o facto da Lei que criou 
o Serviço Nacional de Saúde, no seu artigo 7. ${ }^{\circ}$, já contemplar a possibilidade de se aplicarem taxas moderadoras como forma de racionalização da utilização dos serviços e ainda o facto de se aplicarem um conjunto de isenção, nomeadamente a não aplicação aos cidadãos economicamente mais desfavorecidos.

Atualmente (2018), as taxas moderadoras são cobradas no acesso:

a) As consultas nos prestadores de cuidados de saúde primários (atenção primária à saúde);

b) Nos hospitais e em outros estabelecimentos de saúde públicos ou privados convencionadas (com acordos de cooperação com o Serviço Nacional de Saúde em regime de complementaridade);

c) Na realização de exames complementares de diagnóstico e terapêutica em serviços de saúde públicos ou privados convencionados (com exceção dos efetuados em regime de internamento em sessão de hospital de dia)

d) No atendimento em serviços de urgência

Na prática o paciente quando recorre a um serviço de saúde público tem, além do pagamento prévio que realizou com seus impostos, de contribuir com parte do custo da intervenção, que embora residual é pesado para algumas famílias. Por esse motivo e de forma a não comprometer o acesso, a legislação que regulam a fixação de taxas moderadoras apresenta uma diferenciação dos utentes em três categorias: os isentos, não isentos ou dispensados do pagamento de taxas moderadoras (REPÚBLICA PORTUGUESA, 2016a).

Nos termos da legislação em vigor (REPÚBLICA PORTUGUESA, 2011), estão isentos do pagamento os pacientes que possuem as determinadas condições apresentadas na tabela seguinte:

Quadro 2 - Requisitos de isenção/dispensa do pagamento de taxas moderadoras na saúde em Portugal

As grávidas e parturientes;

Os menores de 18 anos de idade;

Os pacientes com grau de incapacidade igual ou superior a $60 \%$;

Os pacientes em situação de insuficiência econômica, bem como os dependentes do respetivo agregado familiar;

Os doadores de sangue;

Os doadores vivos de células, tecidos e órgãos;

Os bombeiros;

Os doentes transplantados; 
Os militares e ex-militares das Forças Armadas que, em virtude da prestação do serviço militar, se encontrem incapacitados de forma permanente;

Os desempregados com inscrição válida no Centro de Emprego bem como o respetivo cônjuge e dependentes;

Os jovens em processo de promoção e proteção a correr termos em comissão de proteção de crianças e jovens ou no tribunal, que não possam comprovar a sua condição de insuficiência econômica;

Os jovens que se encontrem em cumprimento de medida tutelar de internamento, de medida cautelar de guarda em centro educativo ou de medida cautelar de guarda em instituição pública ou privada, por decisão proferida no âmbito da Lei Tutelar Educativa, que não possam, por qualquer forma, comprovar a sua condição de insuficiência econômica;

Os jovens integrados em qualquer das respostas sociais de acolhimento por decisão judicial proferida em processo tutelar cível que não possam, por qualquer forma, comprovar a sua condição de insuficiência econômica;

Os requerentes de asilo e refugiados e respetivos cônjuges ou equiparados e descendentes diretos.

Fonte: República Portuguesa (2011).

Contudo, na prática o impacto das taxas moderadoras não é significativo para a despesa em saúde, representando cerca de 1,68\% do total da despesa pública do SNS (DGO, 2018). Além disso, são $61 \%$ os cidadãos que se encontram isentos/dispensados do pagamento das taxas moderadoras, o que contribui relevantemente para a sua pouca expressão.

\section{CONCLUSÃO}

Desde a primeira versão da Constituição da República Portuguesa até à mais recente, o direito à saúde foi sempre salvaguardado.

A materialização do direito constitucional à proteção da saúde por parte do Estado ocorreu no ano de 1979 com a criação de um Serviço Nacional de Saúde universal, geral e gratuito na sua redação original.

Durante muitos anos, a universalidade e a generalidade da provisão permaneceram inalteradas, no entanto a gratuidade passou a ser "tendencial" desde a revisão constitucional de 1989, sendo aplicadas taxas moderadoras aos cuidados de saúde prestados no SNS e que se mantêm até hoje com um conjunto de isenções e dispensas de pagamento legalmente definidas, que tiveram sempre em conta as condições socioeconómicas dos cidadãos, garantindo o direito de acesso aos mais desfavorecidos.

A Constitucionalidade da ação política é sujeita a uma análise, avaliação e julgamento por parte do Tribunal Constitucional. Desde 1979 foram já várias as ações desenvolvidas que resultaram num conjunto de Acórdãos que sempre salvaguardarem o cumprimento dos princípios de universalidade, generalidade e tendencial gratuidade.

\section{REFERÊNCIAS}

CAMPOS, António. Reformas no setor da saúde: o fio condutor. Coimbra: Almedina, 2008. 
CAMPOS, António; SIMÕES, Jorge. O percurso da saúde: Portugal na Europa. Coimbra: Almedina, 2011. (Coleção Olhares sobre a saúde).

CANOTILHO, Gomes; MOREIRA, Vital. Constituição da Republica anotada. Coimbra: Almedina, 2007.

DGO - DIREÇÃO GERAL DO ORÇAMENTO. Síntese da execução orçamental 2017. Lisboa: DGO, 2017. Disponível em: https://www.dgo.pt/execucaoorcamental/Paginas/Sintese-daExecucao-Orcamental-Mensal.aspx?Ano=2018\&Mês =Janeiro. Acesso em: 20 fev. 2018.

FERNANDES, Adalberto Campos. Combinação público-privado em saúde: impacto no desempenho no sistema e nos resultados em saúde no contexto português. Lisboa: Instituto Superior de Ciências Sociais e Política, 2015.

MIRANDA, Jorge; MEDEIROS, Rui. Constituição Portuguesa Anotada. Coimbra: Almedina, 2005.

NOVAIS, Jorge. Constituição e Serviço Nacional de Saúde. Coimbra: Almedina, 2010a.

NOVAIS, Jorge. Constituição e Serviço Nacional de Saúde. Revista de Direitos Fundamentais \& Justiça, v. 4, n.11, p.85-109, abr./jun. 2010b.

NOVAIS, Jorge. Direitos fundamentais: trunfos contra a maioria. Coimbra: Almedina, 2006.

NOVAIS, Jorge. Os princípios constitucionais estruturantes. Coimbra: Almedina, 2011.

NUNES, Alexandre Morais. Reformas na gestão hospitalar: análise dos efeitos da empresarialização. Lisboa: Instituto Superior de Ciências Sociais e Políticas, 2016.

REPÚBLICA PORTUGUESA. Administração Central do Sistema de Saúde. Circular normativa n $\mathbf{n}^{\mathbf{8}}$ : alteração do regulamento de aplicação de taxas moderadoras. Lisboa: ACSS, $2016 \mathrm{a}$.

REPÚBLICA PORTUGUESA. Decreto 10/04 de 1976. Constituição da República Portuguesa. Diário da República, n. ${ }^{\circ}$ 86/1976, Série I de 10 de abril de 1976.

REPÚBLICA PORTUGUESA. Decreto-Lei nº113/2011. Regula o acesso às prestações do Serviço Nacional de Saúde por parte dos utentes no que respeita ao regime das taxas moderadoras e à aplicação de regimes especiais de benefícios. Diário da República, ${ }^{\circ}{ }^{\circ}$ 229/2011, Série I de 29 de novembro de 2011.

REPÚBLICA PORTUGUESA. Despacho n 5911-B/2016. Estabelece disposições para a referenciação do utente, para a realização da primeira consulta hospitalar, em qualquer das unidades hospitalares do Serviço Nacional de Saúde onde exista a especialidade em causa. Diário da República, $n .^{\circ} 85 / 2016,2^{\circ}$ Suplemento, Série II de 03 de maio de $2016 b$.

REPÚBLICA PORTUGUESA. Lei $n^{\circ} 1 / 2005$, de 12 de agosto. Sétima revisão constitucional. Diário da República, n. ${ }^{\circ}$ 155/2005, Série I-A de 12 de agosto de 2005.

REPÚBLICA PORTUGUESA. Lei n 48/90. Lei de Bases da Saúde. Diário da República, n. ${ }^{\circ}$ 195/1990, Série I de 24 de agosto de 1990. 
REPÚBLICA PORTUGUESA. Lei n ${ }^{\circ}$ 56/79, de 15 de setembro. Cria o Serviço Nacional de Saúde. Diário da República, n. ${ }^{\circ}$ 214/1979, Série I de 15 setembro de 1979.

SILVA, Pedro; PESTANA, Maria Helena. Avaliação e atitudes perante os sistemas de saúde europeus numa perspectiva comparada. Lisboa: Imprensa de Ciências Sociais, 2013.

SIMÕES, Jorge; AUGUSTO, Gustavo; FRONTEIRA, Inês. Introduction of freedom of choice for hospital outpatient care in Portugal: Implications and results of the 2016 reform, Health Policy, v.121, n.12, p. 1203-1207, 2017.

Como citar: NUNES, Alexandre Morais; RAPOSEIRO, Rosa. Direito à saúde em Portugal: enquadramento constitucional e o desenvolvimento do serviço nacional de saúde. Revista do Direito Público, Londrina, v. 14, n. 3, p. 35-48, dez. 2019. DOI: 10.5433/24157-108104-1.2019v1 4n3p. 35. ISSN: 1980-511X

Recebido em: 05/08/2018

Aprovado em: 14/01/2019 